\title{
Yield-density relations for apple trees on a dwarfing and a semi-dwarfing rootstock
}

\author{
E. W. M. Verheij* and F. L. J. A. W. Verwer \\ Institute of Horticultural Engineering (ITT), Wageningen, Netherlands
}

Manuscript received: 4 November 1971

\section{Summary}

In a planting system trial with Golden Delicious on M IX and M II, started in 1962, lowdensity plots are compared with high-density plots. The low-density plots -1100 trees per ha on M IX and 660 trees per ha on M II - came into bearing slowly and yields leveled off at about 40 tons per ha. For the high-density plots -3300 and 2260 trees per ha for M IX and M II, respectively - yields quickly increased to about 75 tons per ha in 1967 and 1968, but thereafter yields declined, associated with more intensive pruning and fruit thinning to restore tree vigour and fruit quality. Yield per unit growth was initially somewhat higher but finally much lower in the high-density plots, indicating that fruiting suffered more than growth from competition between trees.

Yield per unit growth was much higher on M IX than on M II, an advantage of decisive importance at high density. Fruit size was slightly better on M IX, and at high density the problems in maintaining fruit size were not as serious as on M II. Growth control in the high-density M II plot became difficult and tree thinning may be advisable.

Under the conditions of the trial the optimum density for Golden Delicious on M IX probably lies above 3000 trees per ha, on M II below 2000 trees per ha. Notions regarding rootstock effects on yield per unit growth, fruit quality, etc. may be misleading if they are not based on comparisons under equal competitive stress.

\section{Introduction}

During the last decades tree numbers per ha for apple orchards have increased rapidly, largely as a result of the change-over towards more dwarfing rootstocks. Around 1950 M IX became the predominant rootstock in the Netherlands. It was generally recommended for the clean-cultivated orchards in the coastal areas at a standard tree spacing of $4 \times 21 / 2 \mathrm{~m}$. In the central and eastern regions more vigorous rootstocks were thought indispensable because the orchards were in grass or the soils rather light; $5 \times 3$ $\mathrm{m}$ was a very common spacing for these trees.

Around 1960 the combination of cultivation along the tree rows with grassed-down alleyways became established, opening the way for a wider use of M IX throughout the country. Meanwhile it was becoming clear that $4 \times 21 / 2 \mathrm{~m}$ was an excessively wide spacing and one or two growers started experiments with much higher densities for or-

* Present addres: H.V.A.-Ethiopia, P.O. Box 3407, Addis Abeba, Ethiopia 
chards on M IX. This development led to the lay-out of a planting system trial at the Regional Experimental Horticulture Station at Horst. The objective was to compare orchards on M IX with those on M II - at the time the most widely used rootstock in the region - at conventional spacing as well as at high density. Growth, yield and fruit quality were thus studied for both rootstocks at 2 levels of inter-tree competition. Preliminary results of this trial have been given by Peerbooms (1967). Light measurements were carried out to relate the findings to competition for light in the crop; the results of the light study will be presened in a subsequent paper.

\section{Experimental methods}

The trial in Horst is an unreplicated comparison of trees on M IX and on M II, both grown at a high and a low (conventional) density. Trees at high density are slender spindles; at low density free spindles are compared with hedged spindles. The densities and planting patterns are listed in Table 1 . As the differences between free and hedged spindle bushes were negligible in comparison with the density effects, the data for these tree shapes have been averaged. Thus results are presented for trees on the 2 rootstoocks, grown at 2 densities.

Each plot consists of one row of Jonathan trees on either side flanked by a row of Golden Delicious trees. Results for Golden Delicious only are presented. The trees were planted as maidens in spring 1962. The plots are arranged as follows:

$\begin{array}{lll}\text { Rootstock } & \text { density } & \text { tree shape } \\ \text { Guard row } & & \\ \text { IX } & \text { high } & \text { slender spindle } \\ \text { II } & \text { high } & \text { slender spindle } \\ \text { II } & \text { low } & \text { free spindle } \\ \text { IX } & \text { low } & \text { free spindle } \\ \text { IX } & \text { low } & \text { hedged spindle } \\ \text { II } & \text { low } & \text { hedged spindle }\end{array}$

Guard row

Yield and fruit grade per plot has been recorded annually; in addition growth and yield per tree have been recorded for 40 trees per plot from 1965 onwards. Measurements per tree include trunk girth $20 \mathrm{~cm}$ above the union, number of fruit and weight

Table 1. Density, planting pattern and tree shape (round figures).

\begin{tabular}{|c|c|c|c|c|}
\hline \multirow[t]{3}{*}{ Tree shape } & \multicolumn{4}{|l|}{ Rootstock } \\
\hline & \multicolumn{2}{|l|}{ M IX } & \multicolumn{2}{|l|}{ M II } \\
\hline & $\begin{array}{l}\text { density } \\
\text { (trees } / \text { ha) }\end{array}$ & $\begin{array}{l}\text { planting } \\
\text { pattern }(m)\end{array}$ & $\begin{array}{l}\text { density } \\
\text { (trees/ha) }\end{array}$ & $\begin{array}{l}\text { planting } \\
\text { pattern (m) }\end{array}$ \\
\hline $\begin{array}{l}\text { Free spindle } \\
\text { Hedged spindle }\end{array}$ & 1100 & $\begin{array}{l}4 \times 21 / 4 \\
31 / 2 \times 21 / 2\end{array}$ & 660 & $\begin{array}{l}5 \times 3 \\
41 / 4 \times 31 / 2\end{array}$ \\
\hline Slender spindle & 3300 & $\times 1$ & 2260 & $31 / 2 \times 11 / 4$ \\
\hline
\end{tabular}


of fruits. Tree trunks were first measured in the summer of 1965; subsequent measurements were made in winter. The absence of guard trees between the plots caused considerable and reciprocal border effects where the high- and low-density areas meet. Therefore the 2 rows on either side of the border have been excluded in the presentation of data.

The orchard is situated on a deep, fertile sand soil. Tree vigour is only moderate, in spite of sprinkler irrigation. The alleyways are in grass, the soil under the tree rows is treated with herbicides, pruning was light during the early years and more severe when the time came to rejuvenate the fruiting wood. During the last few years fruit thinning was essential; in 1969 and 1970 carbaryl was used for this purpose.

\section{Results}

Growth and yield per tree

In Fig. 1 tree growth, expressed as trunk cross-sectional area, is shown against time. The growth curves demonstrate the effects of competition: from 1965 onwards the growth per tree at high density falls back. This is not a pruning effect: for the trees on M IX the weight of prunings per tree was very similar at high and low density; for the closely spaced trees on M II pruning weights per tree were comparatively small until the end

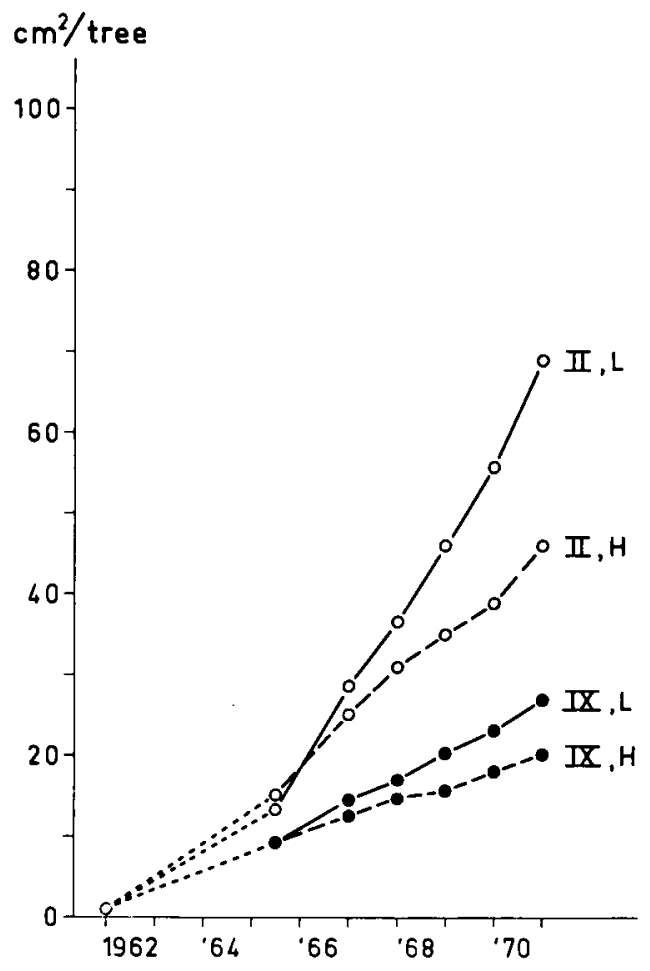

60
Fig. 1. Growth per tree, represented by trunk cross sectional area in $\mathrm{cm}^{2}$ per tree against time, in relation to rootstock and density. $\mathrm{L}=$ low density; $\mathrm{H}=$ high density; $\mathrm{II}=$ rootstock $\mathrm{M} \mathrm{II} ; \mathrm{IX}=\mathrm{M} \mathrm{IX}$. 
Table 2. Annual yield in $\mathrm{kg}$ per tree. in relation to rootstock and density.

\begin{tabular}{|c|c|c|c|c|}
\hline \multirow[t]{2}{*}{ Year } & \multicolumn{2}{|l|}{ M IX } & \multicolumn{2}{|l|}{ M II } \\
\hline & $1100 \mathrm{trees} / \mathrm{ha}$ & 3300 trees $/ \mathrm{ha}$ & 660 trees $/$ ha & 2260 trees $/$ ha \\
\hline 1963 & 0 & 2.3 & 0 & 2.3 \\
\hline 1964 & 0.8 & 2.9 & 0.6 & 3.7 \\
\hline 1965 & 13.1 & 11.0 & 9.9 & 15.6 \\
\hline 1966 & 9.9 & 10.6 & 15.1 & 17.4 \\
\hline 1967 & 39.2 & 23.2 & 70.2 & 34.8 \\
\hline 1968 & 37.4 & 22.0 & 63.3 & 33.4 \\
\hline 1969 & 35.9 & 18.4 & 64.8 & 26.8 \\
\hline 1970 & 38.3 & 17.2 & 55.0 & 18.0 \\
\hline
\end{tabular}

of 1968 when at high density hard pruning became necessary. Up till 1965 trees at high density grew as well as those at low density, in the case of trees on M II somewhat better. This may be a result of more sheltered growing conditions at high density or of lighter formative pruning.

Fig. 1 also shows the superior vigour of the trees on M II. It takes some time before the larger tree size on M II results in a heavier crop per tree. This is shown by the mean annual yields per tree, listed in Table 2. From 1966 onwards, yield per tree in M II is consistently higher than on M IX. Density effects are also apparent from the yield data in Table 2. Initially yields per tree tend to be higher at high density, an effect that has also been observed in other trials (Verheij, 1968; Verheij and Verwer, 1971). In addition to shelter and lighter pruning, better pollination (more pollinators, nearer to the receptor trees) may have contributed to the higher yields. However, in due course competition manifests itself in higher yields for the larger trees at low density.

If density and rootstock affect both yield and growth per tree, the question arises whether the ratio of fruiting to growth is also affected. To answer this question Fig. 2 depicts how cumulative yield per $\mathrm{cm}^{2}$ trunk cross-sectional area changes with tree age.

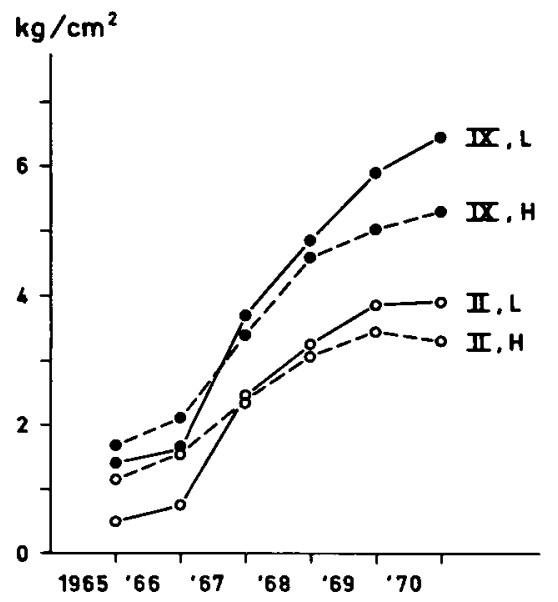

Fig. 2. Yield per unit growth, in $\mathrm{kg}$ fruit per $\mathrm{cm}^{2}$ trunk cross-sectional area, against time; for trees on M IX and on M II grown at low and at high density. $\mathbf{L}=$ low density; $\mathbf{H}=$ high density; $\mathbf{I I}=$ rootstock M II; IX = rootstock $M$ IX. 
The ratio increases as trees come into full bearing and it is much higher for trees on M IX. Moreover, for trees on M IX the ratio is still improving at the end of the period under study, whereas for trees on M II it is near its maximum in 1970. At high density the ratio is initially higher, but the first good yield of the low-density plots, in 1967, reverses the order. During the following years the superiority of cumulative yield in relation to tree size at low density becomes more prominent. These findings suggest that high density favours yield per unit growth in the young orchard, but as trees get bigger fruiting suffers rather more from mounting inter-tree competition than does growth.

\section{Growth and yield per ha; fruit size}

Fig. 3 shows the growth per ha against time; growth is expressed as 'basal area' (the sum of cross-sectional areas of all trunks). It appears that basal area growth is far superior at high density. The curves for the M IX plots lag behind those for the corresponding M II plots, showing that the closer spacings for M IX are not adequate to make up for the lesser vigour of this stock. At high density especially the difference in basal area between M II and M IX is substantial; growth in the M II plot was rather vigorous in relation to tree spacing and from 1968 onwards it became increasingly difficult to accomodate the yearly growth. Summer pruning was therefore carried out in this plot.

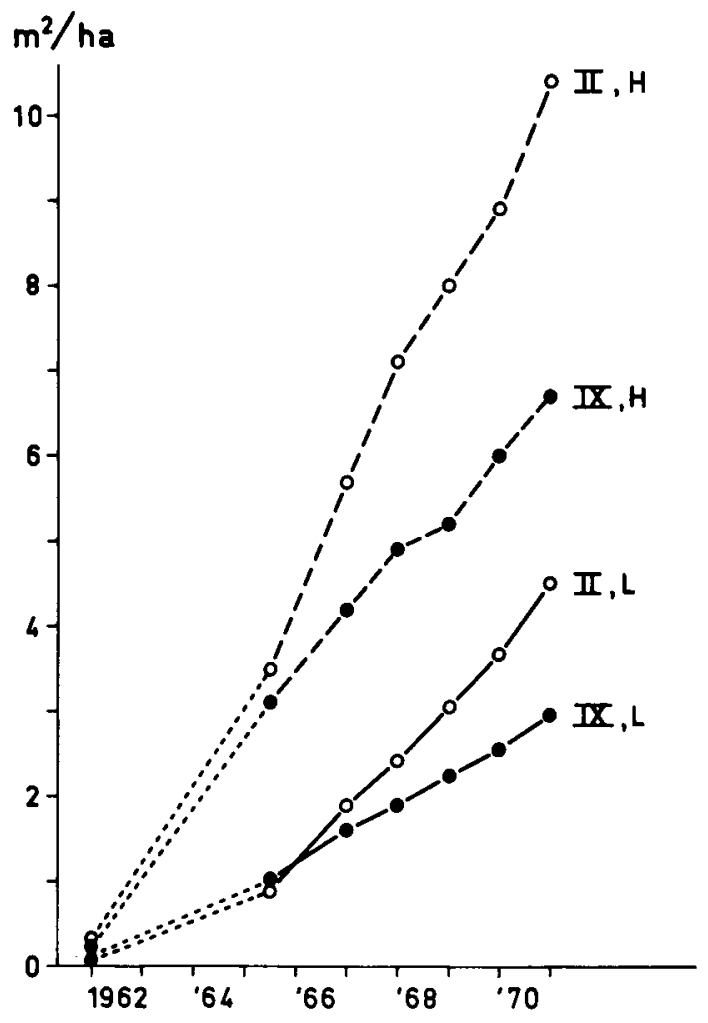

Fig. 3. Growth per unit area, expressed as basal area in $\mathrm{m}^{2}$ per ha against time; in relation to rootstock and density. $\mathrm{L}=$ low density; $\mathbf{H}=$ high density; II $=$ rootstock $\mathrm{M}$ II; IX $=$ rootstock $M$ IX. 


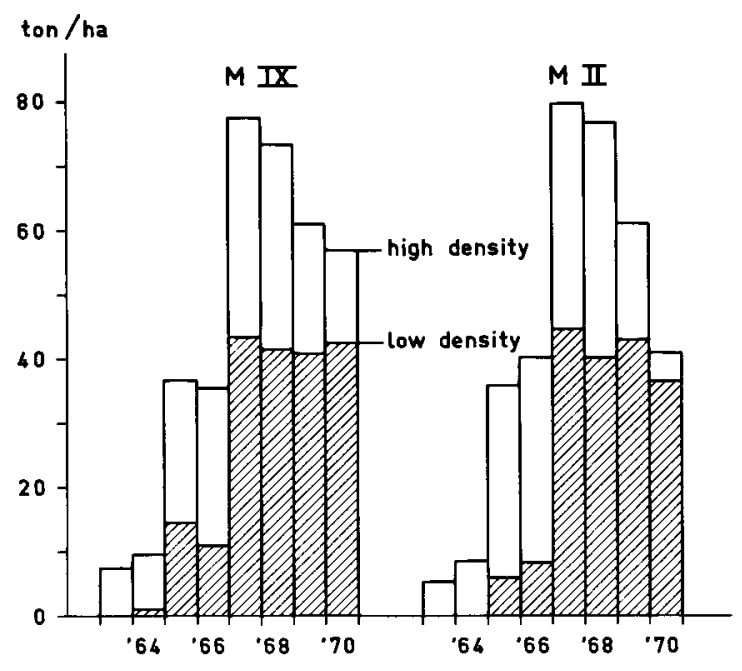

Fig. 4. Annual yield per ha for trees on M IX and on M II, grown at low and at high density.

The curves in Fig. 3 show more clearly than those in Fig. 1 that the rate of growth is fairly steady. Only at high density the growth rate is temporarily depressed, presumably as a result of heavy yields in 1967 and 1968.

The annual yields per ha are shown in Fig. 4. The relatively low yield in 1966 makes it convenient to distinguish two 4-year periods: during 1963-66 the orchards come into bearing, during 1967-70 the high yield indicates that the orchards are coming of age.

The interesting points in Fig. 4 are the similarity of yield level for plots on M IX and and on M II, the superiority of yield in the high-density plots and the constancy of yield at low density during 1967-70, as compared to the declining yields in the high density plots.

The finding that yields are very much the same, facillitates the comparison of both stocks. The effect of density on yield is spectacular. Both high-density plots come into bearing rather early, yielding between 35 and 40 tons per ha in the 4 th and 5 th year from planting. In the following 2 years they produce yields of more than 70 tons per ha.

Presumably, at that age the trees were in their prime and together constituted a near ideal canopy at high density. Thereafter the yield level had to be brought down by pruning and fruit thinning to maintain tree vigour and fruit quality. Nevertheless, without exception the yields in the high-density plots are superior to those in the lowdensity plots.

Data on mean weight per fruit are listed in Table 3. Fruit size declines as trees get older, but with a minimum of $154 \mathrm{~g}$ it remains very acceptable at low density. The differences in weight per fruit between trees on M IX and on M II in these low-density plots are remarkably small. At high density M IX lives up to its fame as a fruit-size-promoting rootstock, but the preceding evidence strongly suggests that this is a result of more severe inter-tree competition in the M II plot, rather than a rootstock effect. The fluctuation in weight indicates that at high density it is more difficult to maintain fruit size. This appears to be associated with the heavy crops at high density.

In 1967 yields of over 70 tons per ha do not result in inferior weight per fruit in comparison with low density. Keeping up this yield level in 1968, however, leads to a consi- 
Table 3. Mean weight per fruit in $\mathrm{g}$, in relation to rootstock, density and tree age.

\begin{tabular}{llllll}
\hline Year & M IX & & & M II \\
\cline { 2 - 3 } \cline { 5 - 6 } & 1100 trees/ha & 3300 trees/ha & & 600 trees/ha & 2260 trees/ha \\
1965 & 178 & 181 & & 176 & 143 \\
1966 & 185 & 179 & 177 & 157 \\
1967 & 156 & 160 & 156 & 157 \\
1968 & 161 & 139 & 154 & 131 \\
1969 & $*$ & 166 & $*$ & 142 \\
1970 & $*$ & 155 & & & 167 \\
\hline
\end{tabular}

* Lacking data. Grading after harvest showed that for trees on M IX in 1969 fruit size distribution was as good as, and in 1970 was better than, at high density; for trees on M II it was much better in 1969 and poorer in 1970 than at high density.

derable reduction of fruit size and also reduces the growth rate. Lowering of the yield level to 60 tons per ha in 1969 restores fruit size on M IX, but on M II fruit size (and growth rate) are still reduced. A further reduction to 40 tons per ha in 1970 leads to a recovery of fruit size and growth rate on M II; for M IX on the other hand the yield level in 1970 is maintained at nearly 60 tons per ha, but this causes weight per fruit to decline to $155 \mathrm{~g}$.

Evidently increased intra-tree competition between growth and fruiting in years with a heavy crop, is an ideal means of reducing competition between trees. However the results indicate that this possibility is limited by the requirement that growth must be adequate to allow the fruit to reach an acceptable size. Moreover, as trees get older growth appears to be regulated increasingly by inter-tree competition, rather than by fruiting. Thus, towards the end of the period under study -9 years from planting declining yields per ha, annual fluctuations in mean weight per fruit and - for M II problems in accomodating tree growth indicate that the spectacular initial advantages of the high-density plots cannot be perpetuated indefinitely.

\section{Discussion}

\section{Effects of density}

In spite of the simple nature of the trial the effects of density are very convincing. Cumulated yields of the 9-year-old trees amount to 360 and 350 tons per ha for the high-density plots on M IX and M II, respectively, as against 195 and 180 tons for the low-density plots. These differences in yield amply compensate for the extra investment in trees at high density and for the reduction in fruit size in some years. The year-toyear fluctuations in fruit size may be due to lack of experience with high-density orchards, but the interdependence of crop size and fruit size implies that fruit size could only have been maintained at the expense of yield per ha.

There were no problems in respect of orchard management, apart form controlling growth in the high-density M II plot. Should this problem aggravate in the future to the extent that crop or fruit quality or both become inferior to those at low density, then grubbing of part of the trees might be the best solution. Results of a planting system 
experiment with Jonathan in Hungary (Verheij, 1968) indicate that tree thinning in highdensity plots may lead to quick and substantial improvements in yield, yield per unit growth and fruit quality. Hilkenbäumer and Engel (1969) obtained better yields from Golden Delicious and Jonathan on M IV following thinning from $3 \times 1.5$ to $3 \times 3 \mathrm{~m}$ than from the trees which had been spaced at $3 \times 3 \mathrm{~m}$ from the start.

The need for tree thinning would substantiate the impression that the density of 2260 trees per ha for M II is excessive; with a less extreme tree number per ha growth control in the mature orchard would have been easier, presumably associated with higher yields per ha. Thus it would seem that under the conditions of the trial the optium density for Golden Delicious on M II lies below 2000 trees per ha.

In spite of a spacing equivalent to 3300 trees per ha, there are no signs of undue competitive stress in the high-density $\mathrm{M}$ IX plot. The yield level may have to be further reduced to safeguard fruit quality, but it should be possible to keep yields above the 40 tons per ha level of the low-density plot for years to come. There is no reason to believe that intermediate densities would have outyielded the high-density treatment. This is also indicated by the findings of Hilkenbäumer and Engel in respect of Golden Delicious and Jonathan on M IX, grown at 1100, 1670, 2200 and 3300 trees per ha. The cumulated yields for 8 -year-old trees at the 2 intermediate densities were higher than for the lowest density but much lower than for the highest density. So it looks as if under the prevailing experimental conditions the optimum density for Golden Delicious on M IX lies above 3000 trees per ha.

\section{Comparison of $M I X$ and $M I I$}

The densities for trees on M IX and on M II have been arbitrarily chosen, but the near-equality of yields provides an acceptable basis for comparing fruit quality and growth on both stocks. Basal area growth in the M IX plots was much smaller than in the corresponding M II plots, so that trees on M IX produced a hgher yield per unit growth than trees on M II. This favourable characteristic of M IX has been reported by Preston (1958), Roberts and Mellenthin (1964), and others, but here it is confirmed at equal yield levels per ha and at 2 densities. This is important because the results show that the ratio declines at high density.

The advantage of an inherently higher ratio of fruiting to growth comes to the fore at high density. To produce the same yield per ha, orchards on a rootstock with a lower ratio have to accomodate extra growth, leading to overcrowding. It seems therefore unlikely that the excellent performance of the high-density $\mathbf{M}$ IX plot could have been matched - in respect of both yield and fruit quality - by trees on M II, even if the high-density treatment for M II had been less extreme.

With regard to fruit quality, trees on $\mathrm{M}$ IX have been only slightly better than on $M$ II, at least at low density. At high density fruit quality on M IX was only in 1968 and perhaps in 1970 poorer than at low density, but for M II high density resulted in smaller fruits and poorer colour in most years. However it has already been argued that this may be due to the severe competitive stress in the high-density M II plot, rather than to the influence of the rootstock.

The dependence of yield per unit growth and fruit quality on density raises some doubt as to the value of conventional rootstock trials, where spacing is equal for trees on all stocks. The big trees on invigorating stocks in such a trial may suffer severe competition, whereas for the small trees on dwarfing stocks competition may be virtually absent. Yield per unit growth and fruit quality of such small trees may be far better than under 
the competitive conditions of a well-designed orchard. It seems therefore likely that the superior fruit quality, generally attributed to trees on M IX, stems in part from the relatively wide spacings for these trees, in older commercial orchards as well as in rootstock trials.

\section{Acknowledgment}

The authors wish to thank the staff of the Regional Experimental Horticulture Station at Horst for the management of the trial and the assistance in the collection of data.

\section{References}

Hilkenbäumer, F. \& G. Engel, 1969. Dichtpflanzungen mit Kernobst. Erwerbstobstbau 11 (7): 1-23. Peerbooms, H., 1967. (Tree shape and spacing trial on a sandy soil). Fruitteelt 57: 940-941 (Dutch). Preston, A. P., 1958. Apple rootstock studies: 35 years' result with Cox's Orange Pippin on clonal rootstocks. J.hort.Sci. 33 (3): 194-201.

Roberts, A. N. \& W. M. Mellenthin, 1964. Unusual ratio measures efficiency and vigor. Fruit Grower $18(11): 26-27$.

Verheij, E. W. M., 1968. Yield-density relationships in apple; results of a planting system experiment in Hungary. Publ. Inst. Tuinb. Tech. Wageningen 37: pp. 31.

Verheij, E. W. M. \& F. L. J. A. W. Verwer, 1971. (Horticultural aspects of mechanization in fruit growing). Inst. Tuinb. Tech. Wageningen 64 (Annual Report 1970), p. 143-146 (Dutch, Engl. summ.). 